\title{
Human-animal Relationship Assessment in Horses (Equus caballus) with Different Uses
}

\author{
Eva-Andrea DIUGAN ${ }^{1}$, Marina SPINU ${ }^{1}$, Silvana POPESCU ${ }^{2}$ \\ ${ }^{1)}$ Department of Infectious Diseases; \\ 2) Department of Animal Hygiene and Welfare, University of Agricultural Sciences and Veterinary Medi- \\ cine Cluj-Napoca, Calea Manastur, No. 3-5, 400372, Cluj-Napoca, Romania; \\ * Corresponding author e-mail: lazarevaandrea@yahoo.com
}

Bulletin UASVM Veterinary Medicine 71(2) / 2014,

Print ISSN 1843-5270; Electronic ISSN 1843-5378

DOI:10.15835/buasvmcn-vm: 10718

\begin{abstract}
Several researchers using different behavioural tests assessed the behavioral responses of adult horses toward humans. According to the results of the current scientific research, understanding and improving the quality of human-horse relationship can lead to many benefits for both humans and horses. The aim of the study was to assess comparatively the human-animal relationship in groups of horses with different uses, in order to reveal if significant differences can be found depending on the type of their activity.

A total number of 128 adult horses were assessed (mares, stallions and geldings) in several locations, used for working, equitation and reproduction. Three simple behavioural tests were employed (the voluntary approach test, the avoidance distance measuring and the ability to touch the horse including the measuring of its tolerance for human physical contact) to assess the human-horse relationship. The results were statistically processed and interpreted.

After comparing the results, statistically significant differences were found in the quality of the human-horse relationship in horses used for different activities. Comparing the results for several horse categories from the same facility (where it was possible) and used for the same type of purpose, the differences were not statistically significant.

As the results of the present study show, the human-horse relation can show significant differences depending on the use of the horses, most probably because the differences in the type of their previous experiences with humans. Improving the quality of the human-horse relationship can lead to a higher level of human safety when working with these animals.
\end{abstract}

Keywords: behavioural tests, horses, human-horse relationship

\section{INTRODUCTION}

From the moment that horses were domesticated there were certainly continuous interactions between humans and horses, leading to a relationship of a given quality. As Estep and Hetts (1992) define it, the human-animal relation represents the degree of closeness or distance between the animal and human, the reciprocal perception of the two protagonists, developing based on and expressed by the mutual behavior of them (Waiblinger et al., 2006). Thus the humananimal relationship is established through a dynamic process in which the previous interactions between the animal and humans ensure the basis for a stabile relationship that will have a feedback effect on the nature and perceptions of the future interactions (Estep and Hetts, 1992).

Generally, this type of relationship needs either mutual individual recognition or the generalization by the animal of the experiences with a human also on other humans (Wainblinger et al., 2006). As Hanggi (2005) states, generalization is an adaptive trait by which a behaviour conditioned by a specific stimulus is triggered also by other similar stimuli. 
The importance of a positive human-horse relationship is widely recognized nowadays, irrespective to the purpose of keeping the horse. Sankey et al. (2010) states that the behaviour of the personnel working with horses may have a strong impact, a significant correlation existing between the repeated positive human-horse interactions and the friendly reactions and responses of the horses toward humans. Understanding the quality of the human-horse relationship and improving it can lead to many benefits both for the welfare and the performance of the horses and for the human efficiency and safety when working with these animals.

The aim of this study was to comparatively assess the human-animal relationship in horses with different uses, in order to reveal if significant differences can be found according to their type of activity.

\section{MATERIALS AND METHODS}

Within this study a total number of 128 adult horses of different breeds were assessed: 15 geldings, 17 stallions and 96 mares. A group of 24 horses was composed by riding horses at a private equitation center, 34 horses were horses used for work, owned by several different people and the remaining 70 were at a horse-breeding farm.

Three simple behavioural tests were employed to assess the human-horse relationship: the voluntary approach test, the avoidance distance measuring and the tolerance of the horse for physical contact with a human. The methodology for these tests was adapted following the descriptions of Rousing and Waiblinger (2004), Lansade and Bouissou (2008) and GoreckaBruzda et al. (2011).

In the voluntary approach test the horses were without any contention, alone or in group, depending on the given situation. The assessor approached calmly, without gesturing the horses, to a distance of about 6-7 $\mathrm{m}$ and stopped. To begin the test, the assessor said a longer sentence, on a calm voice, in order to capture the attention of the horses. Than the assessor stayed still, looking in the direction of the horses but without trying eye contact with these, during 5 minutes, with the possibility to prolong the test with one more minute. Where a group of horses was assessed, additional observers were employed to record the results. For each horse the approach time was noted in seconds (the time passed from the beginning of the test until the horse approached to a distance below $2.5 \mathrm{~m}$ ) and if the animal voluntarily touched the assessor. If a horse did not approach the assessor in 5 minutes, the recorded time was "longer than $300 \mathrm{~s}$ ".

The avoidance distance measuring test and the tolerance for physical contact with a human were performed in this order, in the same session. The assessor was approaching the horse/horses from a distance of at least $3 \mathrm{~m}$, with steps of about $0.5 \mathrm{~m}$, stopping for $10 \mathrm{~s}$ after each step to allow the behavioral response of the horse to occur. The assessor approached in the direction of the horses' neck/shoulder, with the right arm flexed at $45^{\circ}$. If the horse moved in the opposite direction, the approximate distance was recorded (as avoidance distance). If the horse did not avoid the assessor the tolerance for physical contact was attempted. The assessor tried to touch the horses' neck/shoulder. If the horses avoided the physical contact, the assessor had the possibility to follow the animal for a maximum of 5 steps. The tolerance/intolerance for physical contact was noted for each horse.

The results for the voluntary approach test and the avoidance distance measuring were grouped, establishing categories. For the voluntary approach test the categories set were: bellow $60 \mathrm{~s}$, $61-180 \mathrm{~s}, 181-300 \mathrm{~s}$, and more than $300 \mathrm{~s}$. In the avoidance distance measuring test the distances were: between 0 and $1 \mathrm{~m}$, between 1 and $3 \mathrm{~m}$, and more than $3 \mathrm{~m}$.

The prevalence of horses in each category was calculated. The comparison of the obtained values was made using the Mann-Whitney test or t test, depending on data distribution. The differences were considered significant if $\mathrm{P}<0.05$.

\section{RESULTS AND DISCUSSION}

The results of the voluntary approach test for the horses with different uses are presented in Fig. 1. None of the working horses and only $12 \%$ of the breeding horses approached the stationary assessor in less than $60 \mathrm{~s}$, the differences within this time interval being statistically significant $(\mathrm{P}$ $<0.05$ ). Conversely, the majority of the working horses (70\%) did not approached the assessor at all. For this time interval, the difference was again statistically significant $(\mathrm{P}<0.05)$ between the riding horses and those used for work. In the 


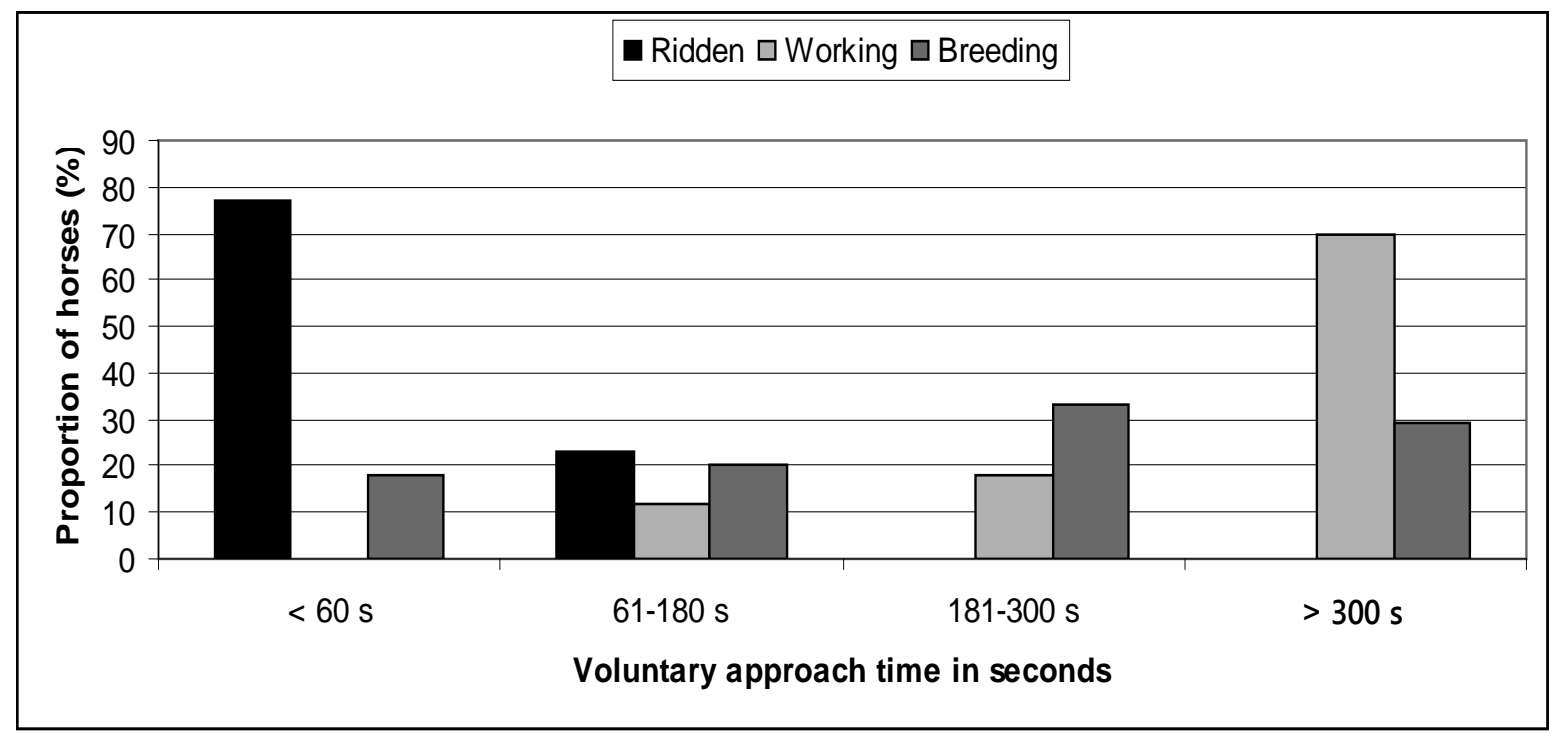

Fig. 1. The comparative representation of the results for the voluntary approach test in horses used for different activities

case of the breeding horses, they approached the stationary human later than the riding horses but the proportion not approaching at all was significantly lower $(\mathrm{P}<0.05)$ than in the case of the working horses.

In a review realized by Hausberger et al. (2008) the authors warn that the results of this type of tests could be influenced by details of the testing procedure, such as the direction of the assessor's gaze, his or her body posture, his or her positioning in spatial relation with the horse. However, the results of other studies, considered generally (Hausberger and Muller, 2002), show that in the horses kept in similar conditions, in the same group, their response to the assessor's presence was similar and it was correlated with the behaviour of their caregiver. In the mentioned review (Hausberger et al., 2008) describe great differences in the tendency of the young horses to approach a stationary human, depending on the farm assessed. These results suggests that the type of daily interactions between humans and horses have strong influence on the horses' perception about humans and their reactions toward people. The finding of the present study, that the working horses did not approach the assessor, may show that these horses do not have a positive perception about humans, possibly seeing them in association with the work they have to perform.

The results for the test measuring the avoidance distance are showed in Fig. 2. Irrespective of the usage category, the majority of the horses accepted the human approach to less than 1 $\mathrm{m}$ (Fig. 2). For this test, the differences were significant $(\mathrm{P}<0.05)$ between the breeding horses and other horse categories only in the case of human avoidance at a distance of more than $3 \mathrm{~m}$. An interesting finding was the fact that none of the working horses avoided the assessor at more than $3 \mathrm{~m}$ (Fig. 2) and this was the horse category with the highest proportion of horses staying still as the human approached them at less than $1 \mathrm{~m}$ (Fig. 2).

The physical contact with the assessor was accepted by $76 \%$ of the riding horses and by $63 \%$ of the breeding horses. In the case of the working horses $87 \%$ tolerated to be touched by the assessor at the first attempt and all the others were touched when the assessor made additional steps (maximum 5), talking with them, in their direction.

Regarding the human avoidance distance a study of Birke et al. (2011) states that irrespective of the degree of familiarization of horses with humans and irrespective if they are alone or in groups, there occurs an avoidance response when a human approaches them at a distance of about $2.5 \mathrm{~m}$. This egocentric barrier can be altered and the human avoidance response can be lowered by habituation of the horses with the human approach and especially when using food rewards (Birke et al., 2011). These argumentations seem to be quite logical, but the fact that the working 


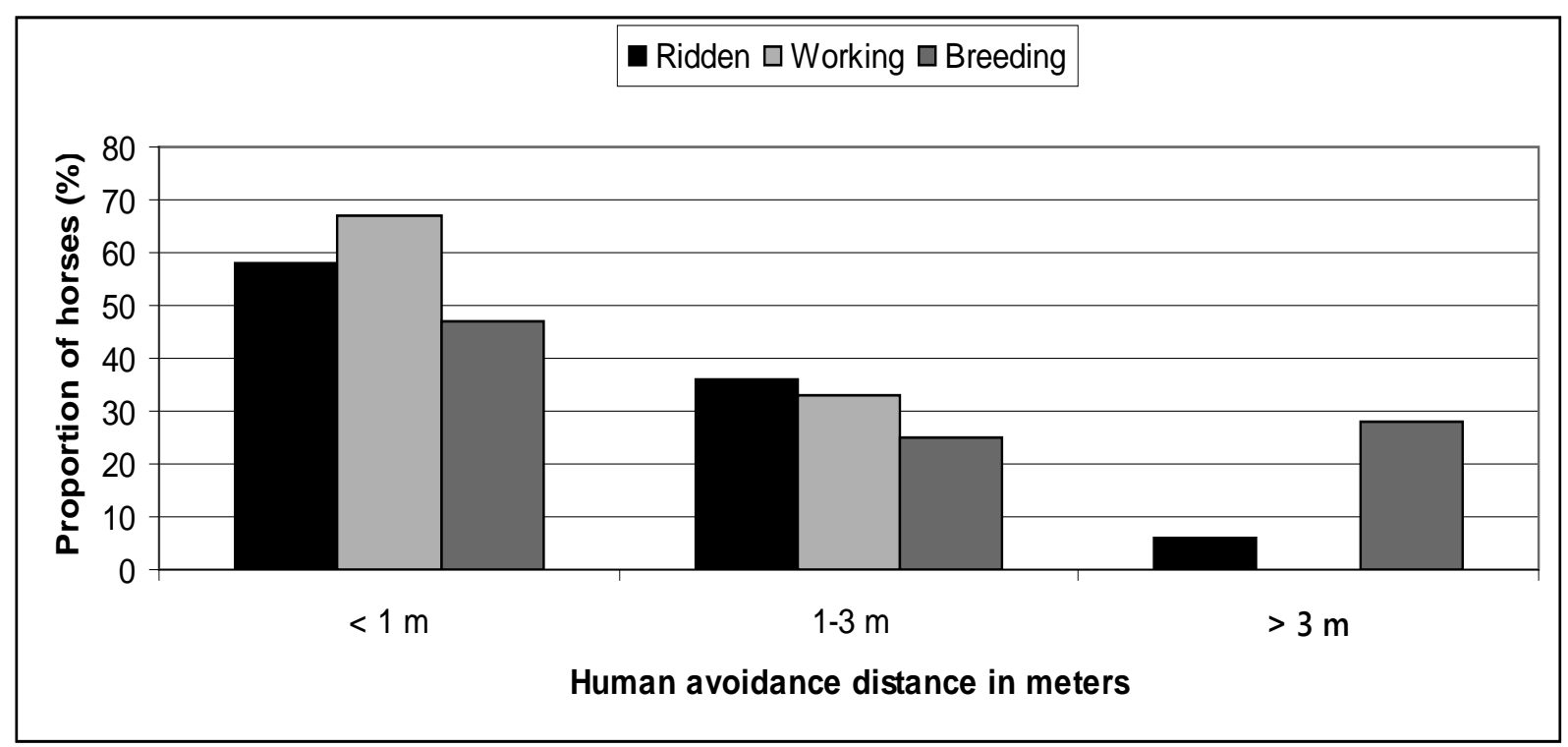

Fig. 2. The comparative representation of the results for the human avoidance distance measuring test in horses used for different activities

horses in the present study did not avoid humans seems to contradict these. Yet the explanation may be the fact that these horses seemed to forget that they could have the possibility to escape from humans, maybe something similar with the concept of learned helplessness, described by Hall et al. (2008).

\section{CONCLUSION}

As the results of the present study show, the human-horse relation can show significant differences depending on the use of the horses, most probably because the differences in the type of their previous experiences with humans. Improving the quality of the human-horse relationship can lead to a higher level of human safety when working with these animals.

\section{REFERENCES}

1. Birke L, Hockenhull J, Creighton E, Pinno L, Mee J, Mills D (2011). Horses responses to variation in human approach, Appl Anim Behav Sci, 134:56-63.

2. Estep DQ, Hetts S (1992). Interactions, relationships and bonds: the conceptual basis for scientist-animal relations. In: Davis, H., Balfour, A.D. (Eds.), The inevitable bond: examining scientist-animal interactions, $\mathrm{CAB}$ International, Cambridge, UK, pp. 6-26.

3. Gorecka-Bruzda A, Jastrzebska E, Sosnowska Z, Jaworski Z, Jezierski T, Chruszczewski MH (2011). Reactivity to humans and fearfulness tests: field validation in Polish Cold Blood Horses, Appl Anim Behav Sci, 133:207-215.

4. Hall C, Goodwin D, Heleski C, Randle H, Waran N (2008). Is there evidence of learned helplessness in horses? J of Appl Anim Welfare Sci, 11:249-266.

5. Hanggi EB (2005). The thinking horse: cognition and perception reviewed. Proceedings of the 51th American Association of Equine Practitioners Annual Convention, Seattle, WA, 246-255.

6. Hausberger M, Muller C (2002). A brief note on some possible factors involved in the reaction of horses to humans, Appl Anim Behav Sci, 76:339-344.

7. Hausberger M, Roche H, Henry S, Visser KE (2008). A review of the human-horse relationship, Appl Anim Behav Sci, 109:1-24.

8. Lansade L, Boissou MF (2008). Reactivity to humans: A temperament trait of horses which is stable across time and situations, Appl Anim Behav Sci, 114:492-508.

9. Rousing T, Waiblinger S (2004). Evaluation of on-farm methods for testing the human-animal relationship in dairy herds with cubicle loose housing systems - testretest and inter-observer reliability and consistency to familiarity of test person, Appl Anim Behav Sci, 35(34):215-231.

10. Sankey C, Henry S, Andre N, Richard-Yris MA, Hausberger M (2011). Do horses have a concept of a person?, PlosOne, 6(3):e18331.

11. Waiblinger S, Boivin X, Pedersen, V, Tosi MV, Janczak AM, Visser K, Jones RB (2006). Assessing the human-animal relationship in farmed species: a critical review, Appl Anim Behav Sci, 101:185-242. 